If hopes of colonizing the Moon are ever to become reality, water needs to be found there. Sizeable amounts of ice could provide Moondwellers with drinking water and, if they split it into its atomic components, hydrogen for fuel and oxygen to breathe. If lunar water is scarce, colonizers would have to carry water and fuel with them from Earth, or perhaps extract hydrogen from the rocks, either of which could be hugely expensive.

But a paper published in Nature this week (see page 835) strengthens the argument that radar data previously interpreted as showing ice could reveal nothing more than rough ground.

The Shackleton crater at the Moon's south pole is a good place to look for deposits of water ice, because parts of it are in permanent shadow from the Sun and so perpetually frozen. Areas of the crater's rim are in permanent sunlight; together these factors make it a good candidate for a lunar base.

But scientists have argued for a decade about whether there is really ice in the crater. The evidence for Shackleton containing ice deposits is based on the fact that radar signals reflected off the crater are polarized the same way as the incoming pulse (called a high circular polarization ratio, or CPR) - a property of ice. Rough surfaces have the same effect, but the Moon has few rough areas, because apart from young features such as recent impact craters, the surface has been sandblasted to a fine dust.

But astronomer Donald Campbell, of Cornell University in Ithaca, New York, has never bought this argument. Now he has gathered the highest-resolution radar images made of the Moon so far, and claims that they dash hopes of finding large lumps of ice at Shackleton.

Campbell and his colleagues sent radar signals from the Arecibo radio telescope in Puerto Rico to the Moon, and captured the reflections using the Robert C. Byrd Green Bank Telescope in West Virginia. Campbell says that Shackleton shows the same pattern of high CPR as the similarly shaped Schomberger crater - which is dried out by sunlight. Campbell also found similar patterns in the walls and floors of other young craters. So, he argues, the signal from Shackleton is probably caused by rough rocks.

Campbell did see some evidence of ice at Shackleton, but as dispersed particles in

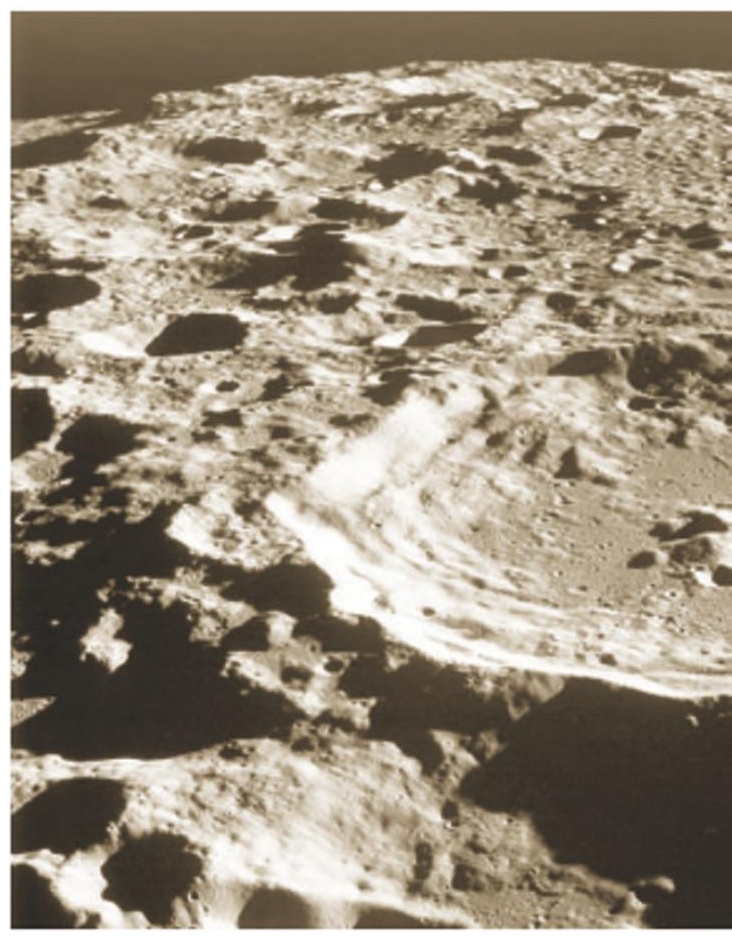

loose rock, not as lumps. He urges those planning Moon missions to take his findings into account. "Planning for future bases on the Moon should be predicated on there being low concentrations of water ice, ${ }^{n}$ he says.

Predictably for such a long-running debate, not everyone agrees. ${ }^{\alpha}$ Don sees one thing and says 'no ice.' I see the same thing and say 'maybe ice," says planetary geologist Paul Spudis of the Lunar and Planetary Institute

\title{
Missing results might have rung warning bell over trial drug
}

The company whose experimental drug left six volunteers critically ill failed to provide regulatory authorities with relevant data before the trial, claim two experts. They say a checklist could help to ensure more rigorous risk assessment for future applications, especially given the increasing popularity of drugs that act on the immune system.

The antibody, called TGN1412, activates the immune system's Tcells, and was being developed by the German company TeGenero. But in the firsthuman tests on 13 March, it triggered a dangerous over-reaction of the immune system calleda cytokine storm. The agency responsible for approving the trial, the UK Medicines and Healthcare Products Regulatory Agency (MHRA), concluded that this was caused by an unexpected biological effect of the drug.

Now two drug-safety specialists who have investigated the case say relevantinfor mation about TGN1412 that might have raised a red flag was missing from the file TeGenero gave the MHRA and other authorities (M. Kenter and A. Cohen Lancet 368 , 1387-1391; 2006). "If assessorshad known, they probably would have started asking questions," says Marcel Kenter, executive director of the Central Committee on Research Involving Human Subjects in The Hague, Netherlands, which also assesses drugs for clinical trials. His co-author is Adam Cohen of the Centre for Human Drug Research in Leiden.

Kenter and Cohen identified several key pieces of data that were absent from TeGenero's file. For example, they say that tests in mice given a humanized immune system had shown that the antibody caused T-cell numbers todecline, perhaps because they were so fired up they committed suicide. These data were published online in early $M$ arch by researchers, including those at TeGenero (N. Legrand et al. Blood 108, 238-245; 2006).

The authorsalsosay the company failed tomention key differences between the amino-acid sequence of the antibody receptor in rhesus monkeys on which the drug was initially tested and the human sequence. The differencesmight

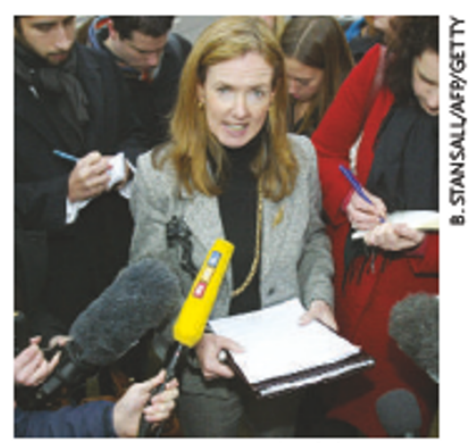

Six volunteers almost died during the TGN1412 trial. 


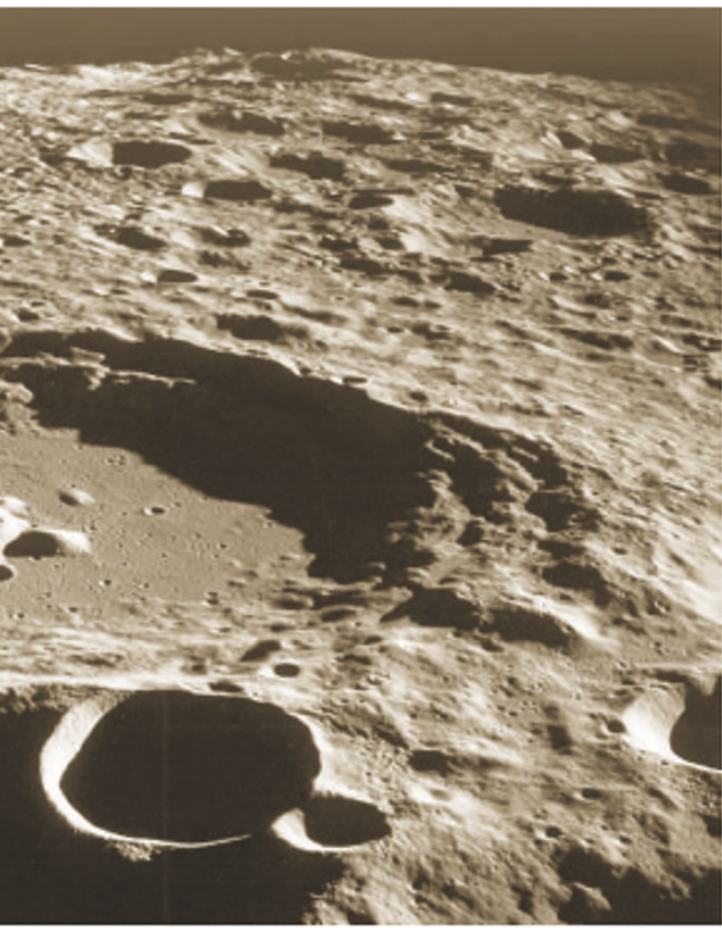

5. On the rocks: astronomers might have mistaken

$\$$ rough craters for lunar ice deposits.

in Houston, Texas. Spudis has believed there is ice on the Moon since the 1994 Clementine mission found high CPR in dark polar regions of the Moon. In 1998, spectrometers on NASA's Lunar Prospector found high levels of hydrogen in the same areas, again suggesting the presence of ice.
Spudis disagrees that the radar signals from Shackleton and Schomberger craters are the same: "Those patterns look different to me." The CPR signal from Schomberger weakens as the crater deepens, consistent with roughness at its rim, Spudis says, whereas the signal at Shackleton starts halfway down the crater and continues deeper in, as might be expected from ice deposits (see Figure 2, page 837).

Spudis is involved with NASA's Lunar Reconnaissance Orbiter (LRO), set to launch in October 2008, which aims to provide a more detailed map of the Moon. In April, NASA announced that the mission would also include a probe that, bycrashing into the Moon, might clear up the ice debate. The probe will split in two, with cameras and a spectrometer on the upper stage recording and analysing the plume of material produced by the lower stage's impact with the Moon. The rest of the probe will crash into the Moon 15 minutes later.

A strong signal of water vapour from the impact could confirm the presence of ice. But an absence of water vapour is unlikely to end the debate, as Spudis argues that the probe could simply hit a dry patch.

The only way to find out for sure will be to land on the Moon and take a sample, says Spudis. Bernard Foing, project scientist on the European Space Agency's Smart-1 lunar orbiter - which ended its three-year mission by crashing into the Moon on 3 September agrees, and is lobbying hard for the agency to develop a lunar lander that could be launched by 2012 .

Katharine Sanderson

JOHNS HOPKINS

$\begin{array}{llllllllll}\mathbf{U} & \mathrm{N} & \mathrm{I} & \boldsymbol{V} & \mathrm{E} & \mathbf{R} & \mathrm{S} & \mathrm{I} & \mathrm{T} & \mathrm{Y}\end{array}$

MASTERS DEGREE

- Open Houses Oct. \& Nov. RSVP Online Now.

Evening and Weekend Classes

- Earn Your Degree Onsite and Online

- Conveniently located in Washington, D.C. Baltimore, MD Rockville, MD Online.

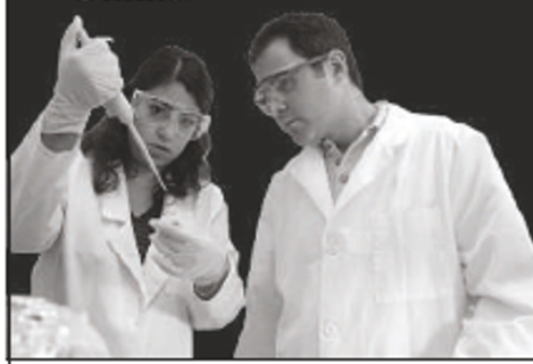

MS in Environmental Sciences and Policy

MS in Biotechnology MS in Bioinformatics MS in Biotechnology/
MBA Joint Degree

MS in Bioscience Regulatory Affairs

Certificate in Biotechnology Enterprise

LEARN MORE AND APPLY ONLINE

antibody would bind more strongly to human than to monkey cells, and perhaps cause a more severe reaction.

Thomas Hanke, chief scientific officer at now-insolvent TeGenero, says all relevant information wasgivento the MHRA before the trial. Although some of TeGenero's studies were carriedout in rhesus monkeys, he says the compary used cynomolgusmonkeys for toxicological studies because the antibody-receptor sequence of the cynomolgus monkey is identical to the humanone.

The MHRA says that at the time of TeGenero's application, senior assessors judged the data submitted to be adequate. But in a preliminary July reportinto the incident, an expertscientific group recommended that rules for such phase I clinical studies be tightened to improve the safety of volunteers.

The Paul Ehrlich Institute in Langen, Germany, had also approvedan application from TeGenero toc arry out a similar trial. Its president, Johannes Löwer, says assessors there did ask TeGenerofor additional information during the approval process and received it. "I'm not sure [a company] is obliged to include these data but they did provide them, so they were thinking about the their relevance," he says.

Kenter and Cohen recommend that regulatory bodies such as the MHRA adopt a checklist during risk assessments to ensure that they have all the information ona drug's mechanism of action and the effects of human exposure to similar agents. Löwer agrees, and says the Ehrlich Institute already operatesa similar checklist, but that other agencies, with less expertise in basic research, might not.

TGN1412 is thought to be an exceptional case. Even so, Kenter says the lessonsare particularly important because of the increasing number of drugs that are designed to work specifically inhumans and somay have side effects that are difficult to predict from animal trials. Helen Pearson
匹 